\title{
Triglycerides, independent of Ferriman Gallwey Score, is a main determinant of free testosterone index in PCOS [version
}

\section{1; peer review: 2 approved]}

\author{
Andon Hestiantoro(i1,2, Putri Deva Karimah33, Amalia Shadrina33, Budi Wiweko1,2, \\ R. Muharam (D1,2, Brilliant Putri Kusuma Astuti1,2

\begin{abstract}
${ }^{1}$ Reproductive Immunoendocrinology Division, Department of Obstetrics and Gynecology, Faculty of Medicine Universitas Indonesia, Dr. Cipto Mangunkusumo General Hospital, Jakarta Pusat, DKI Jakarta, 10430, Indonesia

2Indonesian Reproductive Medicine Research and Training Center (Inarepromed, Faculty of Medicine Universitas Indonesia Jakarta, 10430, Indonesia

${ }^{3}$ Department of Obstetrics and Gynecology, Faculty of Medicine Universitas Indonesia, Dr. Cipto Mangunkusumo General Hospital, Jakarta Pusat, DKI Jakarta, 10430, Indonesia
\end{abstract} \\ (Indonesian Medical Education and Research Institute (IMERI), Dr. Cipto Mangunkusumo General Hospital, Jakarta Pusat, DKI
}

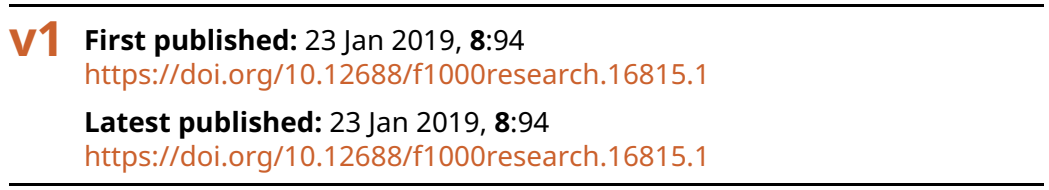

\section{Abstract}

Background: Polycystic Ovarian Syndrome (PCOS) is the most common endocrinopathy in women of reproductive age, affecting 5$20 \%$ of women worldwide. Hyperandrogenism, as the primary characteristic of PCOS, is not always present in every patient. The hyperandrogenic phenotype of PCOS patients is influenced by both hormonal and metabolic dysfunctions. Therefore, this study aims to determine the correlation between hormone profile, lipid profile, and clinical profile with free testosterone index in subjects with PCOS.

Methods: This prospective cross-sectional study was conducted in the Dr. Cipto Mangunkusumo General Hospital between July 2014 and December 2016. The study involved 76 women with PCOS, who were classified into 2 subgroups: 39 subjects in the hyperandrogenism group and 37 subjects in the non-hyperandrogenism group. Each subject underwent physical examination, blood sample collection, and USG examination. Bivariate analysis was done using independent ttests and Mann Whitney U-tests, while multivariate analysis was done using logistic regression.

Results: Triglyceride and testosterone level showed weak $(r=0.232, p$ $=0.044)$ and moderate $(r=0.460, p ; 0.001)$ positive correlation with FTI, while SHBG level showed moderate negative correlation ( $r=$ $0.483, p ; 0.001$ ). Triglyceride was also found to be determinant of hyperandrogenism condition in PCOS patient (OR $0.02,95 \% \mathrm{CI}$ $0.00-0.04, p=0.013)$. However, there was no significant difference observed between FGS and hyperandrogenism ( $p=0.43$ ).

Conclusions: Triglycerides, testosterone, and SHBG were associated

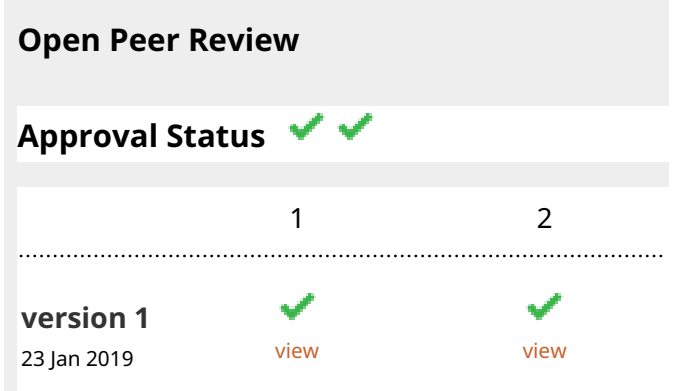

1. Xue Lian Li, Fudan University, Shanghai,

China

Shanghai Key Laboratory of Female

Reproductive Endocrine-Related Diseases,

Shanghai, China

Dan-Feng Du, Fudan University, Shanghai,

China

Shanghai Key Laboratory of Female

Reproductive Endocrine-Related Diseases,

Shanghai, China

2. Zheying Min $(\mathrm{D}$, Peking University Third

Hospital, Beijing, China

Peking University, Beijing, China

Any reports and responses or comments on the article can be found at the end of the article. 
with hyperandrogenism in PCOS patients, while FGS showed no such association.

\section{Keywords}

Polycystic Ovarian Syndrome, Hyperandrogenism, Free Testosterone Index, Hirsutism, Ferriman Gallwey Score, Triglyceride

Corresponding author: Andon Hestiantoro (hestiantoro@gmail.com)

Author roles: Hestiantoro A: Conceptualization, Data Curation, Formal Analysis, Funding Acquisition, Investigation, Methodology, Supervision, Validation, Writing - Original Draft Preparation, Writing - Review \& Editing; Karimah PD: Data Curation, Formal Analysis, Investigation, Methodology, Writing - Original Draft Preparation; Shadrina A: Formal Analysis, Project Administration, Writing - Original Draft Preparation; Wiweko B: Conceptualization, Supervision; Muharam R: Conceptualization, Supervision; Astuti BPK: Project Administration, Writing - Original Draft Preparation, Writing - Review \& Editing

Competing interests: No competing interests were disclosed.

Grant information: The author(s) declared that no grants were involved in supporting this work.

Copyright: ( $) 2019$ Hestiantoro A et al. This is an open access article distributed under the terms of the Creative Commons Attribution License, which permits unrestricted use, distribution, and reproduction in any medium, provided the original work is properly cited. Data associated with the article are available under the terms of the Creative Commons Zero "No rights reserved" data waiver (CC0 1.0 Public domain dedication).

How to cite this article: Hestiantoro A, Karimah PD, Shadrina A et al. Triglycerides, independent of Ferriman Gallwey Score, is a main determinant of free testosterone index in PCOS [version 1; peer review: 2 approved] F1000Research 2019, 8:94 https://doi.org/10.12688/f1000research.16815.1

First published: 23 Jan 2019, 8:94 https://doi.org/10.12688/f1000research.16815.1 


\section{Introduction}

Polycystic Ovarian Syndrome (PCOS) is the most common endocrinopathy in women of reproductive age, affecting 5-20\% of women, depending on the diagnosis criteria used ${ }^{1}$. PCOS is a complex disorder with a wide range of physical manifestation which is primarily characterized by hyperandrogenism or hyperandrogenemia, chronic anovulatory cycle, and polycycstic ovarian morphology. PCOS patients are considered to be at increased risk of developing several co-morbidities, such as diabetes, dyslipidemia, dysmetabolic syndrome, hypertension, obesity, obstructive sleep apnea, mental health disorders, and increased risk of cardiovascular diseases ${ }^{2-4}$.

Hyperandrogenism is one of the hallmark pathophysiological features of PCOS. Along with insulin resistance, hyperandrogenism causes metabolic derangements and some cutaneous symptoms, such as hirsutism, acne, and androgenic alopecia. The extent of hyperandrogenic clinical presentation varies among individuals and is affected by several factors, such as genetic polymorphism, inappropriate epigenetic reprogramming, metabolic factors, and other environmental factors ${ }^{3,5}$. An intricate interrelationship between environmental factors and aberrant micro-RNA expression has been proposed as the epigenetic mechanism underlying the development of PCOS 5 . It can be implicitly recognized that the phenotypic heterogeneity may illustrate the differences in their underlying genetic and metabolic pathophysiology, including the abnormalities of insulin regulation and lipid metabolism.

Besides its prominent aspect in the pathophysiology of PCOS, hyperandrogenism also possesses a fundamental role in achieving a PCOS diagnosis. Hyperandrogenism, as one of the three diagnostic criteria of PCOS, can be identified with physical examination and laboratory evaluation. Hirsutism is the most frequently found clinical manifestation of hyperandrogenism, accounting for approximately $70-80 \%$ of all PCOS cases $^{3,6,7}$. The modified Ferriman-Gallwey Score (mFGS) is used to measure the degree of terminal hair growth in several body sites and total score of $\geq 8$ is considered hirsutism ${ }^{8}$. Biochemical assessment of hyperandrogenism involves the evaluation of several parameters, such as free testosterone index (FTI), free androgen index (FAI) or dehydroepiandosterone sulfate. Elevated levels of one of those markers indicate the presence of hyperandrogenemia? However, elevated androgen levels are not always accompanied by obvious peripheral manifestations. Many studies found that only half of women with hirsutism have elevated levels of androgen hormones and only one-third of women with elevated androgen hormones have hirsutism ${ }^{7}$. Hirsutism is a multifactorial condition and androgen only plays a partial role in its occurrence. These findings suggest that hirsutism might not be the most suitable marker for identifying the elevation of androgen levels in PCOS patients.

It is important to evaluate further which factors correlate with testosterone levels reflected with free testosterone index in subject PCOS. We hypothesized that the hyperandrogenic phenotype of PCOS patients is influenced by both hormonal and metabolic dysfunctions. Therefore, this study aims to determine the association between hormone profile, lipid profile, and clinical profile with free testosterone index in subjects with PCOS.

\section{Methods}

Study background

This was a cross-sectional study conducted at Dr. Cipto Mangunkusumo General Hospital, Jakarta from July 2014 until December 2016. Sample size was determined using Lemeshow sample size formula as presented below:

$\mathrm{N}=\left(\mathrm{Z} \alpha^{2} \times \mathrm{p}(1-\mathrm{p}) / \mathrm{d}^{2}\right.$

$\mathrm{N}$ represents the minimum sample size. $\mathrm{Z} \alpha$ represents standard normal deviation corresponding to $100 \% \quad \alpha$ (1.96) $\mathrm{p}$ represents the proportion of PCOS patients in Cipto Mangunkusumo General Hospital (45.7\%) d represents precision (12\%) According to that formulation, the minimum sample size of this study was 66.2 subjects. To account for potential post-enrollment drop out, additional $10 \%$ subjects were assigned to the study, resulting in a minimum sample size of 72 subjects. Subjects were recruited in-person consecutively from patients who came to the gynecology clinic with the chief complaint of irregular menstrual cycle. The recruitment of subjects was terminated once the minimum sample size has been achieved. Data and sample collection were performed immediately after patients agreed to participate in this study and were conducted during patient's visit to gynecology clinic. All subjects were recruited based on the inclusion criteria, which included women between the age of 18 and 40 years old, who had been diagnosed with PCOS based on Rotterdam consensus criteria, have not consumed any PCOS or hormonal medication in the past 3 months, and were willing to participate in this study. Women who were pregnant or currently breastfeeding; those with history of uterine and other adnexal abnormalities, disorder of adrenal gland function, primary hypothalamic - hypophyseal disorder, ovarian tumor, disorder of prolactin secretion, unexplained abnormal uterine bleeding, and with previous history of thromboembolic or cerebrovascular disorders were excluded from this study.

\section{Ethics}

The study protocol was approved by Ethics Committee of Faculty of Medicine Universitas Indonesia and Dr. Cipto Mangunkusumo Hospital, with reference number of $818 / \mathrm{UN} 2$. F1/ETIK/X/2016. Prior to the beginning of this study, subjects were informed about the protocol of the study and were asked to sign written consent form.

\section{Baseline measurements}

Those who met the aforementioned criteria then underwent medical history taking and physical examination, including waist circumference, body weight, and body height measurements; hirsutism index through $\mathrm{FGS}^{10}$; and gynecologic examination.

FGS is a visual instrument which is widely used to evaluate the excess growth of terminal hair in several body areas. There are 9 androgen sensitive areas which are assessed in FGS, and each area is assigned with value from 1 to 4 according to the thickness 
of the hair growth. These areas are lip, chin, chest, upper abdomen, lower abdomen, upper arm, thigh, upper back, and lower back. The cut off point at which hirsutism diagnosis is made varies depending on race and ethnicity. However, in general a total score equal to or more than 8 signifies hirsutism.

Ultrasonography was done to assess polycystic features. Blood samples were collected during the initial study for fasting plasma glucose, 2-hour postprandial plasma glucose, insulin, Homeostatic Model Assessment Insulin Resistance (Homa-IR), prolactin, LDL, HDL, Triglyceride, SHBG, TSH, LH, FSH, FTI, and testosterone examination. Subjects were instructed to avoid eating or drinking anything for 9-12 hours before the blood sample is collected. Approximately $10 \mathrm{~mL}$ of venous blood samples were drawn from each subject and were collected in several Vacutainers ${ }^{\circledR}$ blood collection tubes. After initial blood collection, subjects were instructed to have a full-course meal or a meal with at least $75 \mathrm{~g}$ of carbohydrates. Two hours following the meal, venous blood samples were drawn again to evaluate the 2 hour postprandial plasma glucose. All specimens were stored in a $-70^{\circ}$ freezer before being transported to the lab for further analysis. Biochemical analysis was conducted at Prodia clinical laboratory. Fasting and 2-hour postprandial plasma glucose were determined using ARCHITECT Glucose Reagent Kit (Abbott Diagnostics, Illinois, USA). Plasma insulin was determined using ARCHITECT Insulin Reagent Kit (Abbott Diagnostics, Illinois, USA). HOMA-IR was calculated according to this formula $=$ fasting insulin (in $\mu \mathrm{IU} / \mathrm{ml}$ ) $\mathrm{X}$ fasting plasma glucose (in $\mathrm{mg} / \mathrm{dL}$ ). Prolactin level was determined using ADVIA Centaur Prolactin Kit (Siemens Healthineers Global, New York, USA). LDL-C level was determined using Sekisui Cholesterol LDL Kit (Siemens Healthineers Global, New York, USA). HDL-C level was determined using Sekisui Cholesterol HDL Kit (Siemens Healthineers Global, New York, USA). Triglyceride level was determined using ADVIA Chemistry Triglyceride Reagent Kit (Siemens Healthineers Global, New York, USA). SHBG level was determined using ADVIA Centaur Immunoassay Kit (Siemens Healthineers Global, New York, USA). TSH level was determined using ADVIA Chemistry TSHs Reagent Kit (Siemens Healthineers Global, New York, USA). LH level was determined using ADVIA Centaur LH Kit (Siemens Healthineers Global, New York, USA). FSH level was determined using ADVIA Centaur FSH Kit (Siemens Healthineers Global, New York, USA). Testosterone level was determined using Testosterone II Kit (Roche Diagnostics, Risch-Rotkreuz, Switzerland). Free Testosterone Index (FTI) was calculated according to this formula $=$ Total Testosterone (in nmol/L) $/ \mathrm{SHBG}$ (in nmol/L) $\mathrm{x} 100$.

\section{Subject classification}

The subjects were classified into two groups according to the results of their FTI tests: hyperandrogenism and non-hyperandrogenism groups. The diagnosis of hyperandrogenism was made according to subject's FTI level. Subjects with FTI measurement equal to or greater than 5 were classified into hyperandrogenism group, while subjects with FTI measurement less than 5 were classified into non-hyperandrogenism group. Comparative analysis was performed between these two groups based on the variables mentioned above. The primary study outcome of this study was to determine the correlation between FGS and FTI, and also factors that contribute to hyperandrogenism phenotype in PCOS patients.

\section{Statistical analysis}

Data obtained from the subjects were recorded in case registration forms and were analyzed using Statistical Package for the Social Sciences (SPSS) version 20. Univariate analysis was done by converting valid data into tables containing mean and median values, as well as their distribution. Bivariate analysis was conducted using independent T-test and Mann-Whitney U-test to compare variables, such as age, body mass index (BMI), body weight, body height, waist circumference, FGS, fasting blood glucose, 2-hour postprandial plasma glucose, insulin, Homa-IR, prolactin, LDL, HDL, Triglyceride, SHBG, TSH, $\mathrm{LH}, \mathrm{FSH}$, and testosterone, between hyperandrogenism and non-hyperandrogenism groups. $\mathrm{P}<0.05$ was considered significant. Among those variables, multivariate analysis using logistic regression was performed on variables with $\mathrm{p}<0.25$. Finally, correlation analysis was performed using Pearson's and/or Spearman's test according to the normality of data distribution. Correlation analysis was performed to quantify the association between the biochemical parameters and free testosterone index in PCOS patients.

\section{Results}

\section{Baseline characteristics}

The 76 subjects participating in this study were classified into two groups: 37 in the PCOS without hyperandrogenism group and 39 in the PCOS with hyperandrogenism group. Most of the subjects were in their mid-20s, overweight (according to Asia Pacific WHO classification), and had central obesity. The subjects' body weights ranged from 50.5 to $101 \mathrm{~kg}$ and the FGS ranged from 1 to 11 . Most of the subjects showed good blood glucose profiles: $90.8 \%$ subjects had normal fasting blood glucose and $53 \%$ subjects had normal 2-hour post-prandial blood glucose. Approximately $94.7 \%$ and $82.9 \%$ subjects had abnormal LDL and HDL levels, respectively, but most (76.3\%) had normal triglyceride levels. The median of insulin level was $13.6 \mu \mathrm{IU} / \mathrm{ml}$, Homa-IR was 2.89, prolactin level was $9.4 \mathrm{ng} / \mathrm{ml}$, SHBG level was $21.48 \mathrm{nmol} / \mathrm{l}$, TSH level was $1.62 \mu \mathrm{IU} / \mathrm{ml}$, LH level was $10.7 \mu \mathrm{IU} / \mathrm{ml}$, FSH level was $6.3 \mu \mathrm{IU} / \mathrm{ml}$, and testosterone level was $37.55 \mathrm{ng} / \mathrm{dl}$. Details of subject characteristics are shown in Table 1.

\section{Comparison of the two groups}

Within bivariate analysis, significant differences between hyperandrogenism and non-hyperandrogenism group were observed in some characteristics, such as triglyceride level $(p=0.01)$, SHBG level $(p=0.01)$, and testosterone level $(p=0.04)$. The hyperandrogenism group had significantly higher level of triglyceride and testosterone, but lower SHBG level. On the other hand, no significant difference was observed between hirsute appearance, which was measured with FGS, and FAI $(\mathrm{p}=0.43)$ (see Table 2).

Spearman analysis was conducted to evaluate the correlation between these factors and FTI. From the analysis, it was found 


\section{Table 1. Characteristics of the Study Population.}

\begin{tabular}{|l|l|}
\hline Characteristic & Value $(\mathbf{n}=\mathbf{7 6})$ \\
\hline Age & $28(23-35)$ years old \\
\hline Body mass index & $27.6(21.5-41) \mathrm{kg} / \mathrm{m}^{2}$ \\
\hline Body weight & $0.6(50.5-101) \mathrm{kg}$ \\
\hline Waist circumference, cm & $92.01 \pm 9.79 \mathrm{~cm}$ \\
\hline Ferriman Gallwey score & $3(1-11)$ \\
\hline Fasting blood glucose & $90(68-105) \mathrm{mg} / \mathrm{dL}$ \\
\hline 2-hour post prandial Blood glucose & $90112.5(56-237) \mathrm{mg} / \mathrm{dL}$ \\
\hline Insulin level & $13.6(8.9-36.8) \mu \mathrm{lU} / \mathrm{ml}$ \\
\hline Homa-IR level & $2.89(2.05-8.99)$ \\
\hline Prolactin level & $9.4(4.4-32) \mathrm{ng} / \mathrm{ml}$ \\
\hline LDL level & $128.5 \pm 31.5 \mathrm{mg} / \mathrm{dL}$ \\
\hline HDL level & $42.51 \pm 6.59 \mathrm{mg} / \mathrm{dL}$ \\
\hline Triglyceride level & $109.5(45-390) \mathrm{mg} / \mathrm{dL}$ \\
\hline SHBG level & $21.48(7.06-65.99) \mathrm{nmol} / \mathrm{l}$ \\
\hline TSH level & $1.62(0.01-8.94) \mu \mathrm{lU} / \mathrm{ml}$ \\
\hline LH level & $10.7 \pm 4.52 \mu \mathrm{lU} / \mathrm{ml}$ \\
\hline FSH level & $6.3 \pm 1.61 \mu \mathrm{lU} / \mathrm{ml}$ \\
\hline Testosterone level & $37.55(6.94-122.6) \mathrm{ng} / \mathrm{dL}$ \\
\hline
\end{tabular}

that triglyceride and testosterone level showed weak $(\mathrm{r}=0.232)$ and moderate $(\mathrm{r}=0.460)$ positive correlations with FTI, while SHBG level showed a moderate negative correlation $(r=-0.483)$ (see Table 3).

Multivariate analysis was conducted using logistic regression, including four variables such as triglyceride level, insulin level, Homa-IR level, and LDL level. Among these variables, triglyceride was found to be an important determinant of hyperandrogenism condition in PCOS patients (Table 4).

Dataset 1. Anthropometric, hirsutism and blood sample data obtained from this study

http://dx.doi.org/10.5256/f1000research.16815.d231733

\section{Discussion}

This study was conducted to determine factors that influence the hyperandrogenism phenotype in PCOS patients, more specifically the concordance between its clinical features and biochemical parameters. Even though hyperandrogenism is one of the pivotal features of PCOS, not every patient with PCOS exhibits such hyperandrogenic phenotype. Pathophysiologically, hyperandrogenism is associated with intense ovarian steroidogenesis due to thecal cell hyperplasia. There are marked increases in GnRH and LH secretion, along with relative deficit in FSH secretion, which resulted in aberrant follicle growth and development, as well as reduced conversion of androstenedione

Table 2. Bivariate Analysis.

\begin{tabular}{|l|l|l|l|}
\hline Characteristic & Non-Hyperandrogenism Group & Hyperandrogenism Group & p value \\
\hline Age & $27(23-34)$ years old & $29(23-35)$ years old & 0.13 \\
\hline Body Mass Index (BMI) & $26.89(21.5-41) \mathrm{kg} / \mathrm{m}^{2}$ & $29(22.9-38.3) \mathrm{kg} / \mathrm{m}^{2}$ & 0.40 \\
\hline Body Weight & $72.5(50.5-101) \mathrm{kg}$ & $70.3(56-97.8) \mathrm{kg}$ & 0.68 \\
\hline Body Height & $1.58(1.5-1.73) \mathrm{m}$ & $1.59(1.45-1.68) \mathrm{m}$ & 0.91 \\
\hline Waist Circumference & $91.83 \pm 11.67 \mathrm{~cm}$ & $92.17 \pm 7.76 \mathrm{~cm}$ & 0.88 \\
\hline Ferriman Gallwey Score (FGS) & $2(1-9)$ & $3(1-11)$ & 0.43 \\
\hline Fasting Blood Glucose & $90(70-103) \mathrm{mg} / \mathrm{dL}$ & $89(68-105) \mathrm{mg} / \mathrm{dL}$ & 0.71 \\
\hline 2-Hour Post Prandial Blood Glucose & $110(78-237) \mathrm{mg} / \mathrm{dL}$ & $115(56-208) \mathrm{mg} / \mathrm{dL}$ & 0.46 \\
\hline Insulin Levels & $13.6(8.9-30.5) \mu \mathrm{lU} / \mathrm{ml}$ & $14.7(9.3-36.8) \mu \mathrm{lU} / \mathrm{ml}$ & 0.07 \\
\hline Homa-IR Levels & $2.75(2.2-7.22)$ & $3.18(2.05-8.99)$ & 0.12 \\
\hline Prolactin Levels & $9.3(4.5-26.2) \mathrm{ng} / \mathrm{ml}$ & $9.8(4.4-32) \mathrm{ng} / \mathrm{ml}$ & 0.62 \\
\hline LDL Levels & $140.62 \pm 26.9 \mathrm{mg} / \mathrm{dL}$ & $46,09 \pm 21,51 \mathrm{mg} / \mathrm{dL}$ & 0.23 \\
\hline HDL Levels & $42.75 \pm 6.49 \mathrm{mg} / \mathrm{dL}$ & $42.28 \pm 6.75 \mathrm{mg} / \mathrm{dL}$ & 0.75 \\
\hline Triglyceride Levels & $95(45-228) \mathrm{mg} / \mathrm{dL}$ & $122(69-390) \mathrm{mg} / \mathrm{dL}$ & 0.01 \\
\hline SHBG Levels & $23.35(11.58-53.91) \mathrm{nmol} / \mathrm{l}$ & $19.54(7.06-65.99) \mathrm{nmol} / \mathrm{l}$ & 0.01 \\
\hline TSH Levels & $1.62(0.01-8.94) \mu l \mathrm{U} / \mathrm{ml}$ & $1.66(0.3-6.11) \mu \mathrm{lU} / \mathrm{ml}$ & 0.15 \\
\hline LH Levels & $10.36 \pm 5.47 \mu \mathrm{U} / \mathrm{ml}$ & $11.02 \pm 3.44 \mu \mathrm{lU} / \mathrm{ml}$ & 0.53 \\
\hline FSH Levels & $6.27 \pm 1.66 \mu l \mathrm{U} / \mathrm{ml}$ & $6.47 \pm 1.57 \mu \mathrm{Ul} / \mathrm{ml}$ & 0.59 \\
\hline Testosterone Levels & $30.36(6.94-122.6) \mathrm{ng} / \mathrm{dL}$ & $40.43(6.94-83.37) \mathrm{ng} / \mathrm{dL}$ & 0.04 \\
\hline
\end{tabular}


and dehydroepiandrosterone to estrogen ${ }^{3,11}$. Insulin resistance also plays a significant role in the development of hyperandrogenism, by increasing the secretion pulse of LH and suppressing the production of SHBG in the liver, thus increasing the level of testosterone ${ }^{3}$.

This study found that there were three biochemical parameters that significantly differed between the two groups and correlated with hyperandrogenism phenotype, which were elevated testosterone and triglyceride levels, as well as decreased SHBG level. Testosterone and triglyceride levels had positive correlations with FTI, while SHBG showed negative correlation with FTI. There is an inverse relationship between SHBG and free testosterone level. SHBG is a glycoprotein that binds and transports sex steroids, such as testosterone and estradiol in the plasma. SHBG concentration is strongly influenced by various factors, such as sex steroid balance, drugs, thyroid hormone, insulin, dietary composition, and liver diseases. Lower level of SHBG means that less testosterone is bound, which results in a higher free testosterone concentration detected in blood plasma ${ }^{12,13}$.

We also found triglyceride levels to be a determinant factor of hyperandrogenism, with a weak positive correlation with FTI.

Table 3. Correlation of Triglyceride, SHBG, Testosterone Level with FTI.

\begin{tabular}{|l|l|l|}
\hline Biochemical Parameter & $\mathbf{p}$ & $\mathbf{p}$ \\
\hline Triglyceride level & 0.232 & 0.044 \\
\hline Testosterone level & 0.460 & $<0.001$ \\
\hline SHBG level & -0.483 & $<0.001$ \\
\hline
\end{tabular}

Dyslipidemia is one of the most commonly found metabolic disturbances in PCOS, occurring in approximately $70 \%$ of PCOS patients. The pathogenic mechanisms underlying this condition are complex and are not yet fully understood. Previous studies found that obesity, hyperandrogenism, and hyperinsulinemic insulin resistance contributed to the development of hypertriglyceridemia in PCOS. Hyperandrogenism and hyperinsulinemia cause defective cathecolamine-induced lipolysis which eventually leads to the increased release of free fatty acids. Free fatty acids then stimulate hepatic overproduction of VLDL with more triglyceride compounds on each VLDL particles. Hyperandrogenism is also believed to have crucial roles in the upregulation of several genes which involved in the catabolism of lipoproteins, such as scavenger receptor B1 (SR-B1) and hepatic lipase (HL). Therefore, it is foreseeable that hyperandrogenic patients will have significantly higher level of triglyceridemia, compared to those with normal androgen concentration $^{14,15}$.

Even though not explicitly stated in this study, an independent relationship was observed between triglyceride level and insulin resistance. A moderate positive correlation was observed between HOMA-IR and triglyceride level in patients with PCOS $(\mathrm{p}<0.001, \mathrm{r}=0.445)$. Triglyceride levels are considered a useful marker in identifying insulin resistance, particularly in patients with metabolic syndrome ${ }^{16}$. As stated above, insulin resistance, along with its compensatory hyperinsulinemia, contributed to triglyceride dysregulation in hyperandrogenic patients with PCOS. Hyperinsulinemia inhibits microsomal triglyceride protein expression which is crucial in the regulation of apolipoprotein B-100 and VLDL production. It also suppresses the removal of triglyceride-rich protein. Insulin resistant PCOS patients are more prone to dysregulation of lipid metabolism compared to those with normal insulin sensitivity $(81 \% \text { vs. } 65 \% \text {, respectively })^{14,15}$.

Table 4. Multivariate Analysis.

\begin{tabular}{|l|l|l|l|l|l|l|l|l|}
\hline Step & Variables & B & S.E. & Wald & df & Sig. & Exp(B) & $\mathbf{9 5 \%}$ CI for Exp(B) \\
\hline 1 & Insulin & 0.274 & 0.216 & 1.611 & 1 & 0.204 & 1.315 & $0.861-2.008$ \\
\hline & Triglyceride & 0.010 & 0.005 & 4.800 & 1 & 0.028 & 1.010 & $1.001-1.019$ \\
\hline & Homa-IR & -0.952 & 0.852 & 1.248 & 1 & 0.264 & 0.386 & $0.073-2.051$ \\
\hline & LDL & -0.010 & 0.008 & 1.682 & 1 & 0.195 & 0.990 & $0.974-1.005$ \\
\hline & Constant & -0.759 & 1.324 & 0.328 & 1 & 0.567 & 0.468 & \\
\hline 2 & Insulin & 0.040 & 0.042 & 0.917 & 1 & 0.338 & 1.041 & $0.959-1.131$ \\
\hline & Triglyceride & 0.009 & 0.004 & 4.411 & 1 & 0.036 & 1.009 & $1.001-1.018$ \\
\hline & LDL & -0.011 & 0.008 & 1.896 & 1 & 0.169 & 0.989 & $0.973-1.005$ \\
\hline & Constant & -0.248 & 1.269 & 0.038 & 1 & 0.845 & 0.780 & \\
\hline 3 & Triglyceride & 0.011 & 0.004 & 5.573 & 1 & 0.018 & 1.011 & $1.002-1.019$ \\
\hline & LDL & -0.010 & 0.008 & 1.685 & 1 & 0.194 & 0.990 & $0.974-1.005$ \\
\hline & Constant & 0.146 & 1.188 & 0.015 & 1 & 0.902 & 1.157 & \\
\hline 4 & Triglyceride & 0.010 & 0.004 & 5.360 & 1 & 0.021 & 1.010 & $1.002-1.019$ \\
\hline & Constant & -1.219 & 0.581 & 4.411 & 1 & 0.036 & 0.295 & \\
\hline
\end{tabular}


A recently published study revealed a two-way relationship between androgen excess and insulin resistance. FAI as the indicator of hyperandrogenism can serve as an indicator of glucose tolerance, as an increase in FAI is usually followed by increases in blood glucose concentration, insulin level, and glucose resistance ${ }^{17}$.

A novel concept, dysbiosis of gut microbiota (DOGMA), has been found to have considerable impact on the pathogenesis of PCOS, particularly through the development of insulin resistance and hypertriglyceridemia. A high-fat/high-sugar diet and obesity are the primary causes of DOGMA, driving increases in the growth of pathogenic microorganisms and suppress the growth good bacteria, which further leads to metabolic endotoxemia (the leakage of lipopolysaccharides produced by Gram-negative bacteria to systemic circulation) and chronic lowgrade inflammatory conditions in the gut. Chronic low-grade inflammation interferes with islet $\beta$-cell proliferation and insulin receptor function, thus resulting in insulin resistance and compensatory hyperinsulinemia. In addition to that, DOGMA also plays a role in the development of dyslipidemia by modulating hepatic and systemic metabolism of lipid and glucose via the elicitation of short-chain fatty acids ${ }^{18-22}$.

Aside from DOGMA, vitamin D deficiency has also been implicated in insulin resistance and dyslipidemic condition commonly found in patients with PCOS. Many previous studies have indicated that PCOS patients with vitamin D deficiency tend to have higher levels of triglyceride and Homa-IR, compared to those with sufficient level of vitamin D concentration. Physiologically speaking, the vitamin D-vitamin D receptor (VDR) complex enacts an important role in regulating several genes, including those involved in glucose and lipid metabolism. Therefore, it is likely that interference in vitamin D concentration would also disrupt the metabolism of glucose and lipid ${ }^{23-25}$. One interesting finding to be noted in this study is the fact that no statistically significant difference was found between FGS and FTI. This finding implicates that the symptoms of hyperandrogenism in our PCOS subjects could not be assessed using FGS. The reason underlying this finding is the fact that clinical signs of hyperandrogenism are not particularly noticeable in PCOS patients in Asian countries, including Indonesia. Hirsutism appearance on each individual depends on their sensitivity to circulating androgens and its variation is influenced by ethnicity. Asian women tend to be less hirsute than Caucasian women, despite the elevated levels of androgen ${ }^{26}$. A number of controversies regarding the extent of testosterone level and FTI in predicting the severity of hirsutism have prevailed upon earlier studies ${ }^{6,27}$. Pathophysiologically, androgens play important role in the growth of terminal hair on several predilection areas which are normally hairy for men, but not for women ${ }^{7}$. However, prior clinical study discovered that only $68 \%$ hirsute PCOS patients were hyperandrogenic and only $63 \%$ hyperandrogenic PCOS patients were diagnosed with hirsutim ${ }^{7,28}$. This implicates that there are other factors that might contribute to hyperandrogenism other than hirsutism, vice versa.

\section{Conclusions}

In conclusion, a high FTI in PCOS patients is associated with high triglyceride levels, high testosterone levels, and low SHBG levels. Ferriman Gallwey score, as an indicator of hirsutism, shows no significant association with FTI. These associations mean that hyperandrogenic phenotype of PCOS patients is influenced by both hormonal and metabolic dysfunctions.

\section{Data availability}

Dataset 1. Anthropometric, hirsutism and blood sample data obtained from this study. DOI: https://doi.org/10.5256/ f1000research.16815.d231733 ${ }^{29}$.

\section{Grant information}

This research received no specific grant from any funding agency in the public, commercial, and non-profit sectors.

\section{Acknowledgements}

The authors would like to thank Yasmin Clinic and patients for their invaluable contributions to this research.
1. Sirmans SM, Pate KA: Epidemiology, diagnosis, and management of polycystic ovary syndrome. Clin Epidemiol. 2013; 6: 1-13. PubMed Abstract | Publisher Full Text | Free Full Text

2. De Leo V, Musacchio MC, Cappelli V, et al:: Genetic, hormonal and metabolic aspects of PCOS: an update. Reprod Biol Endocrinol. 2016; 14(1): 38. PubMed Abstract | Publisher Full Text | Free Full Text

3. Dadachanji R, Shaikh N, Mukherjee S: Genetic Variants Associated with Hyperandrogenemia in PCOS Pathophysiology. Genet Res Int. 2018; 2018: 7624932.

PubMed Abstract | Publisher Full Text | Free Full Text

4. Patel S: Polycystic ovary syndrome (PCOS), an inflammatory, systemic, lifestyle endocrinopathy. J Steroid Biochem Mol Biol. 2018; 182: 27-36. PubMed Abstract | Publisher Full Text

5. Ilie IR, Georgescu CE: Polycystic Ovary Syndrome-Epigenetic Mechanisms and Aberrant MicroRNA. In Adv Clin Chem. Elsevier; 2015; 71: 25-45. PubMed Abstract | Publisher Full Text
6. Leerasiri $\mathrm{P}$, Wongwananuruk $\mathrm{T}$, Indhavivadhana $\mathrm{S}$, et al.: Correlation of clinical and biochemical hyperandrogenism in Thai women with polycystic ovary syndrome. J Obstet Gynaecol Res. 2016; 42(6): 678-683. PubMed Abstract | Publisher Full Text

7. Landay M, Huang A, Azziz R: Degree of hyperinsulinemia, independent of androgen levels, is an important determinant of the severity of hirsutism in PCOS. Fertil Steril. 2009; 92(2): 643-647. PubMed Abstract | Publisher Full Text | Free Full Text

8. Aswini R, Jayapalan S: Modified Ferriman-Gallwey Score in Hirsutism and its Association with Metabolic Syndrome. Int J Trichology. 2017; 9(1): 7-13. PubMed Abstract | Publisher Full Text | Free Full Text

9. Chanukvadze D, Kristesashvili J, Kvashilava N: Correlation of biochemical markers and clinical signs of hyperandrogenism in women with polycystic ovary syndrome (PCOS) and women with non-classic congenital adrenal hyperplasia (NCAH). Iran J Reprod Med. 2012; 10(4): 307-14. PubMed Abstract | Free Full Text 
10. Hohl A, Ronsoni MF, Oliveira Md: Hirsutism: diagnosis and treatment. Arq Bras Endocrinol Metabol. 2014; 58(2): 97-107. PubMed Abstract | Publisher Full Text

11. Jeffrey Chang R, Cook-Andersen $\mathrm{H}$ : Disordered follicle development. Mol Cell Endocrinol. 2013; 373(1-2): 51-60.

PubMed Abstract | Publisher Full Text | Free Full Text

12. Jayagopal $\mathrm{V}$, Kilpatrick $E S$, Jennings $P E$, et al:: The biological variation of testosterone and sex hormone-binding globulin (SHBG) in polycystic ovarian syndrome: implications for SHBG as a surrogate marker of insulin resistance. J Clin Endocrinol Metab. 2003; 88(4): 1528-1533. PubMed Abstract | Publisher Full Text

13. Al Kindi MK, Al Essry FS, Al Essry FS, et al:: Validity of serum testosterone, free androgen index, and calculated free testosterone in women with suspected hyperandrogenism. Oman Med J. 2012; 27(6): 471-4. PubMed Abstract | Publisher Full Text | Free Full Text

14. Diamanti-Kandarakis E, Papavassiliou AG, Kandarakis SA, et al:: Pathophysiology and types of dyslipidemia in PCOS. Trends Endocrinol Metab. 2007; 18(7): 280-285.

PubMed Abstract | Publisher Full Text

15. Alexander CJ, Tangchitnob EP, Lepor NE: Polycystic ovary syndrome: a major unrecognized cardiovascular risk factor in women. Rev Obstet Gynecol. 2009; 2(4): 232-9.

PubMed Abstract | Free Full Text

16. Park SY, Cho YJ, Lee SR, et al:: Triglyceride is a useful surrogate marker for insulin resistance in Korean women with polycystic ovary syndrome. Yonsei Med J. 2015; 56(3): 785-792.

PubMed Abstract | Publisher Full Text | Free Full Text

17. Zhang B, Wang J, Shen S, et al:: Association of Androgen Excess with Glucose Intolerance in Women with Polycystic Ovary Syndrome. Biomed Res Int. 2018; 2018: 6869705.

PubMed Abstract | Publisher Full Text | Free Full Text

18. Tremellen K, Pearce K: Dysbiosis of Gut Microbiota (DOGMA)--a novel theory for the development of Polycystic Ovarian Syndrome. Med Hypotheses. 2012; 79(1): 104-112.

PubMed Abstract | Publisher Full Text

19. Ghazalpour A, Cespedes I, Bennett BJ, et al.: Expanding role of gut microbiota in lipid metabolism. Curr Opin Lipidol. 2016; 27(2): 141-7.

PubMed Abstract | Publisher Full Text | Free Full Text

20. Liu R, Zhang C, Shi Y, et al:: Dysbiosis of Gut Microbiota Associated with Clinical
Parameters in Polycystic Ovary Syndrome. Front Microbiol. 2017; 8: 324 PubMed Abstract | Publisher Full Text | Free Full Text

21. Insenser M, Murri M, Del Campo R, et al:: Gut Microbiota and the Polycystic Ovary Syndrome: Influence of Sex, Sex Hormones, and Obesity. J Clin Endocrinol Metab. 2018; 103(7): 2552-2562. PubMed Abstract | Publisher Full Text

22. Guo Y, Qi Y, Yang X, et al:: Association between Polycystic Ovary Syndrome and Gut Microbiota. PLoS One. 2016; 11(4): e0153196. PubMed Abstract | Publisher Full Text | Free Full Text

23. Garg R, Malhotra J, Singh S, et al.: Relationship between vitamin $\mathbf{d}$ and insulin resistance in polycystic ovary syndrome women. Journal of South Asian Federation of Obstetrics and Gynaecology. 2017; 9(3): 211-215. Publisher Full Text

24. Krul-Poel YH, Snackey C, Louwers $\mathrm{Y}$, et al.: The role of vitamin $\mathrm{D}$ in metabolic disturbances in polycystic ovary syndrome: a systematic review. Eur $J$ Endocrinol. 2013; 169(6): 853-865 PubMed Abstract | Publisher Full Text

25. Rodríguez-Rodríguez E, Ortega RM, González-Rodríguez LG, et al:: Vitamin D deficiency is an independent predictor of elevated triglycerides in Spanish school children. Eur J Nutr. 2011; 50(5): 373-378. PubMed Abstract | Publisher Full Text

26. Wang ET, Kao CN, Shinkai K, et al:: Phenotypic comparison of Caucasian and Asian women with polycystic ovary syndrome: a cross-sectional study. Fertil Steril. 2013; 100(1): 214-218.

PubMed Abstract | Publisher Full Text

27. Amiri M, Ramezani Tehrani F, Nahidi F, et al:: Association between biochemica hyperandrogenism parameters and Ferriman-Gallwey score in patients with polycystic ovary syndrome: A systematic review and meta-regression analysis. Clin Endocrinol (Oxf). 2017; 87(3): 217-230. PubMed Abstract | Publisher Full Text

28. Chang WY, Knochenhauer ES, Bartolucci AA, et al:: Phenotypic spectrum of polycystic ovary syndrome: clinical and biochemical characterization of the three major clinical subgroups. Fertil Steril. 2005; 83(6): 1717-1723. PubMed Abstract | Publisher Full Text

29. Hestiantoro A, Karimah PD, Shadrina A, et al.: Dataset 1 in: Triglycerides, independent of Ferriman Gallwey Score, is a main determinant of free testosterone index in PCOS. F1000Research. 2019. http://www.doi.org/10.5256/f1000research.16815.d231733 


\section{Open Peer Review}

\section{Current Peer Review Status:}

\section{Version 1}

Reviewer Report 07 March 2019

https://doi.org/10.5256/f1000research.18382.r44622

(C) 2019 Min Z. This is an open access peer review report distributed under the terms of the Creative Commons Attribution License, which permits unrestricted use, distribution, and reproduction in any medium, provided the original work is properly cited.

\section{Zheying Min}

${ }^{1}$ Beijing Key Laboratory of Reproductive Endocrinology and Assisted Reproductive Technology, Key Laboratory of Assisted Reproduction, Ministry of Education, Department of Obstetrics and Gynecology, Center for Reproductive Medicine, Peking University Third Hospital, Beijing, China

2 Center for Life Sciences, Academy for Advanced Interdisciplinary Studies, Peking University, Beijing, China

This study describes the correlation between hormone profile, lipid profile and clinical profile with free testosterone index in subjects with PCOS. Triglycerides, testosterone, and SHBG were associated with hyperandrogenism in PCOS patients, while FGS showed no such association. Overall the paper is well structured and written, with results and a strong discussion. However I would have the following comments to the paper:

1. The average BMI of all PCOS patients were more than 25 (27.6). Could obesity influence the statistical analysis of the hormone?

2. There are some evident errors in Tables. For example, In Table 1, is the average value of the body weight 0.6 ?

3. The manuscript must be edited again for typo errors. In the discussion, "There are marked increases in $\mathrm{GnRH}$ and $\mathrm{LH}$ secretion, along with relative deficit in FSH secretion......" I think it should change deficit to deficiency.

4. There are too many references in the discussion part, which should be moved to the introduction part. Because it only includes 9 references in the introduction.

Is the work clearly and accurately presented and does it cite the current literature? Yes

Is the study design appropriate and is the work technically sound? Yes

Are sufficient details of methods and analysis provided to allow replication by others? Yes 
If applicable, is the statistical analysis and its interpretation appropriate?

Partly

Are all the source data underlying the results available to ensure full reproducibility? Yes

Are the conclusions drawn adequately supported by the results?

Yes

Competing Interests: No competing interests were disclosed.

Reviewer Expertise: Mitochondrial Metabolism, Endocrine, Stem Cells

I confirm that I have read this submission and believe that I have an appropriate level of expertise to confirm that it is of an acceptable scientific standard.

\section{Author Response 13 Mar 2019}

Andon Hestiantoro, Faculty of Medicine Universitas Indonesia, Dr. Cipto Mangunkusumo General Hospital, Jakarta Pusat, Indonesia

Dear Dr. Zheying Min, Thank you for your constructive comments and suggestions about our study. Please find below a point-by-point response to your reviews.

The average BMI of all PCOS patients were more than 25 (27.6). Could obesity influence the statistical analysis of the hormone?

There is a possibility that obesity affect the lipid and hormonal profiles of our subjects. Pathophysiologically speaking, obesity is closely related with dyslipidemia as well as insulin resistance, therefore statistical analysis with body mass index adjustment should be performed to independently study the association between PCOS and hormone concentrations.

There are some evident errors in Tables. For example, In Table 1, is the average value of the body weight 0.6 ?

I am sorry for my carelessness and thank you for alerting me about this mistakes. We will revise it soon.

The manuscript must be edited again for typo errors. In the discussion, "There are marked increases in GnRH and LH secretion, along with relative deficit in FSH secretion......" I think it should change deficit to deficiency.

I am sorry again for my carelessness and we also will revise it soon.

There are too many references in the discussion part, which should be moved to the introduction part. Because it only includes 9 references in the introduction.

We will re-arrange it and see if any of these references could be moved to introduction part. 
Once again, thank you for your kind reviews. I look forward to be working and collaborating with you in some future researches.

Cordially, Andon Hestiantoro

Competing Interests: No competing interests were disclosed.

Reviewer Report 05 February 2019

https://doi.org/10.5256/f1000research.18382.r43535

(c) $2019 \mathrm{Li} X$ et al. This is an open access peer review report distributed under the terms of the Creative Commons Attribution License, which permits unrestricted use, distribution, and reproduction in any medium, provided the original work is properly cited.

\section{Xue Lian Li}

1 Department of Gynaecology, OB/GYN Hospital, Fudan University, Shanghai, China

2 Shanghai Key Laboratory of Female Reproductive Endocrine-Related Diseases, Shanghai, China

\section{Dan-Feng Du}

${ }^{1}$ Department of Gynaecology, OB/GYN Hospital, Fudan University, Shanghai, China

2 Shanghai Key Laboratory of Female Reproductive Endocrine-Related Diseases, Shanghai, China

Polycystic Ovary Syndrome (PCOS) is characterized by a series of endocrine and metabolism disturbances, such as insulin resistance, hyperandrogenism, sympathetic dysfunction and chronic low-grade inflammation state ${ }^{1}$ but the inter-relationships between these factors still remain unclear. Hyperandrogenism is the most important manifestation and diagnostic criteria of PCOS, and the Androgen Excess and PCOS Society (AES) has proposed that hyperandrogenism should be the essential condition to diagnose PCOS ${ }^{2}$.There are three forms of serum testosterone (T), 60 $65 \%$ was combined to sex hormones lobulin (SHBG) tightly, 35-40\% was combined to albumin and free testosterone (FT) only consists $1-2 \%$ of total T. Which kind of serum androgen should be measured for diagnosis of PCOS remains controversial. Recently, it is believed assessments of free testosterone levels are more sensitive than the measurement of total T for establishing the existence of androgen excess ${ }^{3}$. Dr. Hestiantoro aims to determine the correlation between hormone profile, lipid profile and clinical profile with free testosterone index in subjects with PCOS, which is worthy of study.

According to the Rotterdam diagnostic criteria, there are at least four phenotypes of PCOS: Subtype I - PCO \& hyperandrogenism \& oligo-ovulation, Subtype II - PCO \& oligo-ovulation, Subtypelll - hyperandrogenism \& oligo-ovulation, Subtype IV - PCO + hyperandrogenism. Different phenotypes may display different endocrine disorders.

Dr. Hestiantoro has shown that high FTI in PCOS patients is associated with high triglyceride levels, high testosterone levels, and low SHBG levels, while Ferriman Gallwey score, as an indicator of hirsutism, shows no significant association with FTI. But another researcher who assessed the 
lipid profile in lean and non-lean PCOS patients, hyperandrogenemia was defined as free androgen index (FAI) $\geq 5$, whose results show higher levels of total cholesterol, high-density lipoprotein cholesterol in lean patients with $\mathrm{FAl}<5$ than in lean patients with $\mathrm{FAl} \geq 5$. There were no differences in lipid profile between non-lean patients with FAI $\geq 5$ and non-lean patients with $\mathrm{FAl}<5^{4}$. Another study has also confirmed these results with Ferriman-Gallwey scores(FGS) and triglycerides are significantly higher in PCOS patients ${ }^{5}$. In another study, PCOS patients with adrenal hyperandrogenism do not exhibit deterioration in insulin resistance and lipid profile despite the higher degree of total androgens ${ }^{6}$.

So what is the real correlation between hormone profile, lipid profile, and clinical profile with free testosterone index in subjects with PCOS? In my opinion, different PCOS phenotypes may display different endocrine and metabolic disorders, and FTI (free testosterone index) is a very valuable potential measurement to diagnose PCOS. It is of great significance to identify endocrine and metabolic characteristics of different phenotypes, but I am afraid the sample size of Dr.Hestiantoro's research is still too small to answer this question, and I suggest the authors may clarify PCOS patients to more detailed phenotypes and may have more interesting findings with a bigger sample size.

\section{References}

1. Shorakae S, Ranasinha S, Abell S, Lambert G, et al.: Inter-related effects of insulin resistance, hyperandrogenism, sympathetic dysfunction and chronic inflammation in PCOS.Clin Endocrinol (Oxf). 2018; 89 (5): 628-633 PubMed Abstract | Publisher Full Text

2. Thessaloniki ESHRE/ASRM-Sponsored PCOS Consensus Workshop Group: Consensus on infertility treatment related to polycystic ovary syndrome.Hum Reprod. 2008; 23 (3): 462-77 PubMed Abstract | Publisher Full Text

3. Goodman NF, Cobin RH, Futterweit W, Glueck JS, et al.: AMERICAN ASSOCIATION OF CLINICAL ENDOCRINOLOGISTS, AMERICAN COLLEGE OF ENDOCRINOLOGY, AND ANDROGEN EXCESS AND PCOS SOCIETY DISEASE STATE CLINICAL REVIEW: GUIDE TO THE BEST PRACTICES IN THE EVALUATION AND TREATMENT OF POLYCYSTIC OVARY SYNDROME--PART 1.Endocr Pract. 2015; 21 (11): 1291-300 PubMed Abstract | Publisher Full Text

4. Spałkowska M, Mrozińska S, Gałuszka-Bednarczyk A, Gosztyła K, et al.: The PCOS Patients differ in Lipid Profile According to their Phenotypes.Exp Clin Endocrinol Diabetes. 2018; 126 (7): 437-444

PubMed Abstract | Publisher Full Text

5. Inal ZO, Erdem S, Gederet Y, Duran C, et al.: The impact of serum adropin and ischemia modified albumin levels based on BMI in PCOS.Endokrynol Pol. 2018; 69 (2): 135-141 PubMed Abstract | Publisher Full Text

6. Paschou SA, Palioura E, Ioannidis D, Anagnostis $P$, et al.: Adrenal hyperandrogenism does not deteriorate insulin resistance and lipid profile in women with PCOS.Endocr Connect. 2017; 6 (8): 601-606 PubMed Abstract | Publisher Full Text

Is the work clearly and accurately presented and does it cite the current literature? Yes

Is the study design appropriate and is the work technically sound? Yes

Are sufficient details of methods and analysis provided to allow replication by others? 
Yes

If applicable, is the statistical analysis and its interpretation appropriate?

Partly

Are all the source data underlying the results available to ensure full reproducibility? Partly

Are the conclusions drawn adequately supported by the results?

Partly

Competing Interests: No competing interests were disclosed.

Reviewer Expertise: Female reproductive endocrine-related diseases, especially PCOS.

We confirm that we have read this submission and believe that we have an appropriate level of expertise to confirm that it is of an acceptable scientific standard.

Author Response 13 Mar 2019

Andon Hestiantoro, Faculty of Medicine Universitas Indonesia, Dr. Cipto Mangunkusumo General Hospital, Jakarta Pusat, Indonesia

Dear Dr. Xue Lian Li,

We are very sorry for the late reply. Thank you for your constructive comments and suggestions about our study.

I admit that one of the limitations of this study is the small sample size, which makes the generalisation of these results to entire PCOS populations difficult. Therefore, future studies with greater sample size and longer observation durations should be established.

As you mentioned previously in your reviews, I did not differentiate and classify the phenotype of PCOS in this study. Distinguishing PCOS phenotypes is an important aspect in the diagnosis and treatment of this syndromes, for different phenotypes might present in different manifestations and required different approach. This might be the reason why some of the findings in our study showed different or even contradictory results to another studies.

Once again, thank you for your kind reviews. I look forward to be working and collaborating with you in some future researches.

Cordially, Andon Hestiantoro

Competing Interests: No competing interests were disclosed. 
The benefits of publishing with F1000Research:

- Your article is published within days, with no editorial bias

- You can publish traditional articles, null/negative results, case reports, data notes and more

- The peer review process is transparent and collaborative

- Your article is indexed in PubMed after passing peer review

- Dedicated customer support at every stage

For pre-submission enquiries, contact research@f1000.com 